\section{Estudo \\ CoDebate}

em CAStão

Plamejamento
Revista Estudo \& Debate, Lajeado, v. 28, n. 1, 2021. ISSN 1983-036X

DOI: http://dx.doi.org/10.22410/issn.1983-036X.v28i1a2021.2672

\title{
O IMPACTO DO INVESTIMENTO EM SAÚDE PÚBLICA NO DESENVOLVIMENTO ECONÔMICO E SOCIAL: UMA ANÁLISE DOS MUNICÍPIOS DO PARANÁ
}

\author{
Marco Aurélio Kasmin ${ }^{1}$
}

\begin{abstract}
Resumo: $\mathrm{O}$ objetivo desse trabalho é analisar se houve impacto do investimento em saúde pública na trajetória de desenvolvimento econômico e social em escala local, cuja delimitação espacial é o município. As informaçóes utilizadas são referentes aos 399 municípios do Estado do Paraná, utilizou-se de dados macroeconomicos agrupados por município para promover uma análise quantitativa em um modelo de dados em painel, relacionando variáveis que representam características dos municípios, variáveis que descrevem sua estrutura de saúde pública e o nível de desenvolvimento sócio econômico, esse último é avaliado de duas formas diferentes, sendo uma forma objetiva, utilizando o PIB per capita, e outra utilizando o índice de desenvolvimento municipal do IPARDES. Toos os dados são secundários oriundos de fontes oficiais. Por meio dessa abordagem metodológica três variáveis se mostraram estatisticamente significativas e positivamente relacionadas ao desenvolvimento local, sendo elas: despesa total per capita, despesa com recursos próprios e saúde complementar $\mathrm{O}$ fato dessas variáveis serem positivas e diferentes de zero nos faz inferir que o sistema público de saúde impacta positivamente sobre a trajetória de desenvolvimento local, os mecanismos de causação são discutidos na abordagem teórica.
\end{abstract}

Palavras-chave: Desenvolvimento regional. Saúde pública. Análise regional. Dados em painel.

\section{IMPACT OF INVESTMENT IN PUBLIC HEALTH ON ECONOMIC AND SOCIAL DEVELOPMENT: AN ANALYSIS OF THE MUNICIPALITIES OF PARANÁ STATE.}

\begin{abstract}
The objective of this work is to analyze whether there was an impact of investment in public health on the trajectory of economic and social development at a local scale, whose spatial delimitation is the municipality. The information used refers to the 399 municipalities in the State of Paraná, macroeconomic data grouped by municipality was used to promote a quantitative analysis in a panel data model, relating variables that represent characteristics of the municipalities, variables that describe their health structure public and the level of socioeconomic development, the latter is evaluated in two different ways, one being objective, using GDP per capita, and the other using the IPARDE's municipal development index. All data is secondary from official sources. Through this methodological approach, three variables proved to be statistically significant and positively related
\end{abstract}

1 Bacharel em Ciencias Econômicas pela Universidade Estadual de Maringá - UEM, Mestre em Gestão e Desenvolvimento pela Universidade Estadual do Oeste do Paraná, Doutorando em Desenvolvimento Regional e Agronegócio pela Universidade Estadual do Oeste do Paraná. Professor do Departamento de Economia da Universidade Estadual do Oeste do Paraná, campus de Toledo. 
to local development, namely: total expenditure per capita, expenditure on own resources and complementary health The fact that these variables are positive and different from zero makes us infer that the public system of health positively impacts the trajectory of local development, the causation mechanisms are discussed in the theoretical approach.

Keywords: Regional development. Regional analysis. Public health. Regional analysis. Panel data.

\section{INTRODUÇÁO}

A saúde pública é organizada em um Sistema Único de Saúde (SUS), que ao mesmo tempo dispóe de serviços, ações e produtos que atende às necessidades de saúde da população e serve como instrumento de fomento ao desenvolvimento econômico e social. É incomensurável a importância do sistema de saúde pública para a sociedade, por exemplo em 2014, foram realizadas 10.626.748 internações, (DATASUS, 2020) sendo gastos 99,2 bilhôes de reais com SUS, (ASSOCIAÇÃO PAULISTA DE MEDICINA, 2015) a nível nacional.

No Estado do Paraná, no mesmo período, foram gastos 5,2 bilhóes de reais no SUS, de acordo com o Conselho Regional de Medicina do Paraná - CRMPR (2020), e foram realizadas 712.976 internaçóes (DataSUS, 2020).

O Estado do Paraná, recorte espacial maior dessa análise, possui uma população de 11.163.018 habitantes, sendo o sexto estado mais populoso do país (IBGE, 2020). Se classificado segundo seu PIB, o Paraná é o quinto estado mais rico do Brasil, atrás de Sáo Paulo, Rio de Janeiro, Minas Gerais e Rio Grande do Sul (IBGE, 2020). O setor agropecuário do Paraná é muito diversificado e altamente produtivo, o estado também possui um progressivo setor industrial, sendo a quarta economia mais industrializada do país e é responsável por mais de $8 \%$ de todas as exportaçôes nacionais (IPEADATA, 2020). Sendo assim, o Estado do Paraná possui grande expressividade dentro do contexto econômico e social brasileiro.

Quanto à saúde, o estado possui 13 hospitais de ensino e 49 cursos na área de ciências da saúde, 52 hospitais especializados e 412 hospitais gerais, 890 postos de saúde, 213 unidades móveis de nível pré-hospitalar de urgência e emergência, 21 unidades móveis terrestres, divididas entre as 21 regionais de saúde que abarcam todo o território paranaense, dados de outubro de 2015 (DataSUS, 2020).

É nesse contexto que esse trabalho procura responder se o sistema público de saúde no Estado do Paraná impacta na trajetória de desenvolvimento e crescimento econômico de sua populaçãa?

Para responder a essa pergunta utilizou-se de um conjunto de dados do Estado do Paraná referente ao sistema de saúde pública, agregados por municípios, indicadores de desenvolvimento e de riqueza. Elaborou-se um modelo para testar se há uma relação positiva do sistema de saúde pública no desenvolvimento do estado, visto que a saúde da populaçáo tende a refletir no sistema produtivo e nos padróes de consumo, como mostrado por Hussain (2009), impactando na produtividade do trabalhador.

O Sistema Único De Saúde do Brasil permite, e busca, uma gestão descentralizada. A gestâo descentralizada é uma estratégia que garante a autonomia dos gestores locais, 
que são simultaneamente os mais interessados nos resultados apresentados, assim como os mais aptos a definir as prioridades diante da realidade local na qual estão imersos. Ao adotar um sistema decentralizado permite-se que cada município desenvolva, a partir de diretrizes centrais, sua gestão, priorizando os problemas locais da população, elenque suas prioridades, e principalmente, desenvolva programas e políticas de saúde pública voltadas exclusivamente para sua população.

Ao elaborar e executar programas e políticas locais, o gestor ao mesmo tempo em que atende à demanda por serviços de saúde, gera também uma demanda para diversos setores produtivos do país como: prestadores de serviços, comércio, transporte e indústrias. Além do impacto econômico, há o impacto social, ao atender milhóes de brasileiros, com a oferta de serviços médicos e de promoção e prevenção da saúde, reduzindo os percentuais de morbidades, amenizando o estado de dor e de sofrimento da população e contribuindo para redução da morbimortalidade, o que promove melhores condiçóes, aumentando a expectativa de vida, e dando dignidade à pessoa humana.

Portanto, o SUS pode ser não apenas um sistema que oferece tratamentos médicos direcionados à doença, como um sistema que tem como principal concepção a promoção e prevenção da saúde, e que pode ainda ser instrumento de fomento, tanto para a qualidade de vida como para o desenvolvimento econômico e social.

Essa forma de gestão decentralizada é há tempos uma tendência mundial (ALMEIDA FILHO, 2001), e fortalece a autonomia do gestor municipal na tomada de decisóes, tornam-se avessas a planos e projetos impostos por esferas distantes de governo, que destoam da realidade local e que por vezes tem decisóes sobre as quais os municípios não foram consultados durante sua elaboração. Esse movimento de endogeneização, mesmo que de forma mais tênue, pode ser observado também na gestão de saúde.

Os municípios vêm buscando cada vez mais autonomia, o chamado movimento de endogeneização, ocorre tanto nas decisôes relacionadas ao destino político e cultural, quanto no uso dos meios e dos recursos utilizados no processo econômico. Isso demonstra que a organização territorial deixou de ter um caráter passivo de simples unidade administrativa, para exercer um papel ativo (AMARAL FILHO, 2001).

Quando a gestão local amplia sua autonomia, passa a dispor de instrumentos para oferecer mais do que os serviços públicos já definidos em lei, mas também, faz confluir os recursos, organizando e estimulando as atividades econômicas locais por meio de suas atividades econômicas e normativas, fomentando assim o desenvolvimento regional. É um processo endógeno e regional que deve englobar de forma mais ampla os atores locais, com maior participação dos agentes locais, dando ao processo um dinamismo único, específico e em consonância com todas as características da região, sejam elas sociais, econômicas e geográficas.

Modelos de gestão decentralizados são apontados por teóricos evolucionistas e institucionalistas como modelos alternativos para o desenvolvimento regional, Boisier (1988) denomina esses modelos como tendo base na "organização social regional", ou como definido por Schmitz (1997), por meio da "ação coletiva”. Este processo tem como base a ampliação da autonomia dos agentes locais, que podem interferir na economia 
local, ao selecionar serviços, produtos e processos que atendam o quesito da regionalização (AMARAL FILHO, 2001).

Esse potencial para o fomento do desenvolvimento pode ser exercido com a adoção da gestão estratégica e do diálogo entre a saúde e os demais setores da gestáo pública local. O processo pode exponencializar os resultados dos limitados recursos públicos, dado a natureza positiva das externalidades geradas pelos investimentos em qualquer área da administração pública. Por exemplo: o desenvolvimento de programas educacionais de promoção à saúde, desenvolvidos junto a estudantes, poderá no futuro gerar a reduçâo de agravos à saúde, e consequentemente, diminuir dispêndios de recursos do sistema público de saúde no tratamento de enfermidades.

Esses programas educacionais poderiam ainda alterar a cultura da populaçáo das próximas geraçóes, levando a uma maior preocupação com a saúde, buscando a prevenção, detecção e diagnóstico precoce de enfermidades, que resultaria em menor número de consultas, internamentos, tratamentos, redução de custos de absenteísmo e maior qualidade de vida.

Como as demais áreas da administração pública podem interferir positivamente sobre a saúde pública, o investimento em saúde também pode ter efeitos positivos sobre às demais áreas. Por exemplo, um sistema mais eficaz, que desenvolva políticas de promoção à saúde do trabalhador que reduziria o absenteísmo por doença ou acidentes, geraria menores dispêndios ao sistema nacional de previdência e seguridade social, assim como, elevaria a produção e consequentemente o Produto Interno Bruto (PIB).

Infelizmente, no Brasil não há dados suficientes para estimar o custo do absenteísmo (PENATTI et al. 2006), mas, como exemplo, na União Europeia, segundo Graça (1999), o custo do absenteísmo por doença e acidentes varia entre 1,5\% e 4\% do PIB, para os países membros do bloco. Tal dispêndio é comparável à taxa média de crescimento anual dos países do bloco. Outro exemplo é a instalação de labaoratórios farmacêuticos subsidiados pelo governo para produção de medicamentos genéricos que geram empregos na regiáo, demandam capacitação da mão de obra, desenvolvimento técnico e tecnológico, pesquisa em saúde e evita a transferência de recursos para laboratórios de fora do país.

É elementar que há possibilidades de os Entes federados contribuírem para o desenvolvimento da regiáo por meio das açôes ofertadas em saúde que envolvem recursos humanos, equipamentos e materiais de consumo adquiridos e a demanda de contratação de serviços de saúde, pela saúde suplementar. Além da movimentação gerada pelo próprio gestor local, existe em um número considerável de vezes à necessidade de contratação de serviços de saúde suplementar que está amparado na Lei Complementar no 147 de 2014 (BRASIL, 2014).

Essa lei permite a contrataçáo de serviços do setor privado sediados local ou regionalmente, podendo os serviços locais exceder o melhor valor apresentado no processo licitatório em até $10 \%$. Isso permite que pequenas empresas sediadas regionalmente não sejam retiradas dos processos de licitação por não acompanharem a estrutura de custos das grandes empresas, que geralmente é menor devido aos ganhos de escala e de escopo. 
Esse instrumento induz à criação de novas empresas e indústrias, podendo também ser utilizado para fomentar, consolidar e ampliar as já existentes, gerando empregos e tecnologia no local.

Outra forma de ação regional estratégica é a ação conjunta, não apenas entre os setores da administração pública, mas, entre as diversas lideranças regionais. Municípios pequenos, que não possuam recursos suficientes, nem uma demanda que justifique o investimento local, podem desenvolver políticas conjuntas, que fomentarão o desenvolvimento regional. Cita-se como exemplo para este tipo de políticas conjuntas os hospitais regionais, as universidades públicas, os consórcios municipais de saúde que geram recursos por meio da contratação de mão de obra qualificada e tecnologias.

O planejamento e execução de políticas estratégicas conjuntas podem simultaneamente suprir as demandas da sociedade por serviços públicos, ao mesmo tempo que fomentam o desenvolvimento econômico e social.

\section{A ABORDAGEM ECONÔMICA DA SAÚDE}

A saúde enquanto área da economia, na qual se enquadra a produção e prestação de serviços relacionados ao bem-estar físico e psicológico dos indivíduos de uma sociedade, mesmo com suas especificidades, igual às demais áreas da economia, é passível de análise segundo os métodos das ciências econômicas. Nero (1995) propóe duas definiçóes para o que denomina-se economia da saúde: Uma definição ampla da economia da saúde seria: "a aplicação do conhecimento econômico ao campo das ciências da saúde, em particular como elemento contributivo à administração dos serviços de saúde” (p.19). Outra forma de definir esse campo de estudo é:

O ramo do conhecimento que tem por objetivo a otimização das ações de saúde, ou seja, o estudo das condiçóes ótimas de distribuição dos recursos disponíveis para assegurar à população a melhor assistência à saúde e o melhor estado de saúde possível, tendo em conta meios e recursos limitados (NERO, 1995, p19).

Ambas as definiçóes se utilizam muito mais de termos econômicos do que das ciências médicas e da saúde. $\mathrm{O}$ que reforça a ideia de que é uma análise econômica de uma área da economia, sem portanto, deixar de lado suas inúmeras especificidades.

A dualidade é o primeiro problema dos pesquisadores da área, o conflito entre a lógica e ética econômica e a da saúde. Enquanto os profissionais da saúde têm uma ética centrada no indivíduo, que entende que a vida não tem preço, cuja atenção médica tem de ser voltada igualmente para todo indivíduo e não se deve poupar recursos para salvar a vida humana, a lógica econômica é voltada para o conjunto, entende-se os recursos como limitados e esses devem ser utilizados de forma parcimoniosa para atender ao maior número possível de indivíduos, e não necessariamente a todos, caso se atinja o limite dos recursos.

A lógica da eficiência acaba por, de certo modo, valorar a vida humana de forma fria e matemática. Os recursos poderiam ser utilizados para o tratamento de uma síndrome rara, por exemplo, mas, serão melhores alocados se atenderem um número maior de indivíduos com doenças de mais simples tratamento, mesmo que isso exija deixar um número menor 
de indivíduos sem tratamento. "Daí existir espaço para conflito entre economistas e profissionais de saúde no que diz respeito à gestão eficiente dos serviços de saúde" (NERO, 1995, p.5).

Mesmo assim as conexóes entre as ciências econômicas e da saúde mantem fortes relaçóes ao estudarem e proporem formas de gestão para os serviços da saúde, sejam públicos ou privados, assim como na análise dos resultados desses serviços na sociedade.

As relaçóes entre a saúde e o desenvolvimento nascem da análise dos resultados dos serviços de saúde no cotidiano da população, e historicamente desde o surgimento de ambos os campos de pesquisa, em 1961, o estatuto do acordo interamericano da Aliança para o Progresso afirmava que saúde constitui um requisito essencial e prévio ao desenvolvimento econômico (VILLA, 1966).

Essaassertivaéuma das percepções a respeito das relações entresaúdeedesenvolvimento, vários países, dentro e fora da citada aliança para o progresso, desenvolveram no século XX sistemas de saúde pública, nos mais diversos modelos, com intuito de oferecer serviços de saúde à população que acabariam por acelerar o processo de desenvolvimento.

Temos como exemplo, o sistema público de saúde do Reino Unido, instituído poucos anos após o final da II Grande Guerra, que possui diversas características observadas entre as teorias do desenvolvimento, entre elas a abordagem regionalista da saúde pública, descrita em 1920 pelo Ministro da saúde do Reino Unido no relatório Dawson (CONILL, 2008).

Como se pode perceber, a economia da saúde não surge como um campo de pesquisa, mas, é fruto da evolução interdisciplinar das análises sobre o tema, feita por pesquisadores da economia, da saúde, gestores, associaçóes internacionais humanitárias e demais profissionais em contato com a problemática.

Dado a crescente importância do tema, em 1981, a Organização Pan-americana da Saúde (OPS) fez um levantamento bibliográfico sobre o tema, com intuito de disponibilizar o material de forma sistemática para cursos de formação de gestores e administradores da saúde. "Nota-se nesse relatório a preocupação de apresentar a seleção de artigos como parte de um universo muito maior, com inúmeras ligaçôes a outros ramos das ciências humanas" (NERO, 1995, p.13). Assim, ao mesmo tempo em que este tipo de trabalho consolida o campo da economia da saúde, mantém seu caráter interdisciplinar, fator fundamental para abarcar todas as especificidades do tema.

\section{A abordagem macroeconômica da saúde.}

A abordagem macroeconômica dos sistemas de provimento de serviços e produtos relacionados à saúde, sejam eles públicos ou privados, os busca inserir nas funçóes de produção que visam explicar o crescimento econômico de uma nação, sua participação na renda nacional, como tais sistemas produtivos impactam na renda per capita, se há efeitos multiplicadores dos recursos empregados em saúde e como o bem-estar da população afeta os níveis de percepção de desenvolvimento.

Essa abordagem econômica da saúde já existe a algumas décadas e tem nesse campo de pesquisa se consolidado na ideia de que a saúde tem um efeito positivo sobre o 
desenvolvimento econômico, como aponta Granados (2002). Esse encadeamento, de forma simples, poderia ser representado da seguinte forma: "Investimentos em saúde > crescimento econômico > produtividade do trabalho > redução da pobreza." (p. 140, tradução nossa).

Segundo Hussain (2009), as principais teorias econômicas que inserem, ou permitem a inserção da saúde nos modelos macroeconômicos são as teorias neoclássicas de Solow (1956) e Swan (1956), essas possibilitam agregar as variáveis da saúde àquelas relativas ao capital humano. Esse modelo separa as variáveis em três grandes grupos, sendo eles: Capital físico, capital humano e tecnologia. Outros modelos econômicos que foram ampliados de forma a englobar à saúde como vetor do crescimento econômico foram os modelos empíricos de contabilidade nacional, de caráter menos determinista. Estes modelos buscam, usando-se do instrumental econométrico, relaçōes entre a saúde e o crescimento econômico. Este trabalho de pesquisa segue tais premissas, buscando por meio da análise de dados em painel, encontrar relaçóes entre a saúde pública e o crescimento econômico, assim como com pela percepção de desenvolvimento, a um nível regional.

O escopo teórico neoclássico do crescimento endógeno pavimentou o caminho para incorporar-se principalmente à educaçáo, e posteriormente, à saúde como importantes determinantes do progresso técnico, tem-se como exemplo, desta tendência os trabalhos de Lucas (1988); Barro (1996); Barro e Sala-i-Martin (1995); Rebelo (1991); Mankiw et al (1992).

$\mathrm{Na}$ linha de pensamento neoclássica, utilizando como base o modelo de Solow, os autores Knight, Loyaza, e Villanueva (1993); Knowles e Owen (1995), introduziram a saúde como fatores de produção e Benhabib e Spiegel (1994); Knowels e Owen (1997) desenvolveram trabalhos inserindo a saúde como vetores determinantes do progresso tecnológico. Ambas as formas ultrapassam o escopo original do modelo de Solow, mas, mantêm as premissas do modelo inicial. Tendo a acumulaçáo de capital humano como o principal motor do crescimento, o efeito positivo da saúde sobre o crescimento econômico é identificado no modelo de crescimento exógeno durante a transiçấo para o estado estacionário ou em modelos de crescimento endógeno, cada um dentro do contexto da optimização intertemporal.

Já a abordagem por modelos empiristas visam relacionar os modelos e volumes de recursos disponíveis em sistemas de saúde com a taxa de crescimento econômico. Mais frequentemente usa-se de análises transversais que reúnam os dados de diferentes nações e comparam-nas entre si, buscando compreender a grandeza do vetor saúde dentro da trajetória de crescimento, sem dispor previamente de um modelo lógico-matemático que presuma essas relaçóes, como fazem os neoclássicos.

Pode-se observar o uso de instrumentos econométricos, mais frequentemente a análise de regressão, que incluem a saúde como um dos vetores que contribuem para o crescimento e desenvolvimento econômico nos trabalhos de Barro (1996); Barro e Lee (1994); Barro, Sala-i-Martin (1995); Bhargava et al. (2001); Bloom, Canning e Malaney (2003); Bloom e Sachs (1998); Bloom e Williamson (1998); Caselli, Esquivel e Lefort (1996); Gallup e Sachs (2000); Hamoudi e Sachs (1999). Dentre eles, a maioria concluiu que há evidencias de que os sistemas de saúde possuem um impacto positivo sobre o crescimento da riqueza 
nacional ou sobre a expectativa de vida da população, poucos trabalhos foram inconclusivos a esse respeito.

Mesmo que estes trabalhos divirjam quanto ao instrumental estatístico utilizado, técnicas de estimação, forma de agregação e tratamento dos dados, universo amostral, periodicidade dos dados e formas funcionais, todos eles concluíram que a dimensão do sistema de saúde impacta positivamente sobre a expectativa de vida da população. Já os modelos que incluíram diretamente o crescimento da riqueza nacional, utilizando-se do PIB absoluto, ou mais frequentemente, do PIB per capita como variável dependente, relataram problemas nos estimadores, mas, frequentemente, a violação da premissa de não multicolinearidade.

Outro ponto a ser considerado ao se analisar os trabalhos de cunho macroeconômico é a diferença entre os universos amostrais, há trabalhos efetuados unicamente com países desenvolvidos, ou outros com, unicamente países em desenvolvimento, há ainda aqueles trabalhos que utilizam ambos. Para tanto é preciso salientar essas diferentes abordagens e buscar alinhar seus resultados de forma lógica para compor uma teoria ampla, que seja válida, com suas especificidades, em qualquer nível de desenvolvimento que a nação se encontre.

As estimativas das regressóes de crescimento do PIB que tem como objeto de estudo países ricos e pobres em conjunto podem diferir significativamente daqueles realizados, tendo como objeto os países ricos e pobres separadamente. $\mathrm{O}$ exame do papel da saúde para as regióes de diferentes níveis requer o uso de indicadores de saúde que são mais capazes de diferenciar os níveis de saúde entre estes países. Por exemplo, esper-se que a expectativa de vida, em países desenvolvidos, tenha pouca variação em função de um aumento na disponibilidade de serviços e produtos da saúde, no entanto, em países em desenvolvimento, um implemento dos sistemas de saúde deve promover um significativo aumento na expectativa de vida.

Weil (2007) sugere que efeito positivo da saúde sobre o PIB é mais forte entre os países pobres. Já para os países desenvolvidos as evidências empíricas existentes sobre o fato de que a formação de capital de saúde (capital humano e tecnologia) estimule o crescimento do PIB de forma mista. Tem-se como exemplo, os trabalhos de Rivera e Currais (1999a, 1999b, 2003) que indicam que o crescimento da disponibilidade de serviços e produtos médicos em países desenvolvidos geraram um efeito positivo sobre a produtividade dos países da Organização para a Cooperação e Desenvolvimento Econômico (OCDE).

Assim percebe-se que, dado o nível de desenvolvimento de um país, os ganhos decorrentes de um aumento dos sistemas de saúde podem não ser significantes. Esse fato pode ser explicado retomando o princípio dos rendimentos marginais decrescentes, principio este que afirma que à medida que se amplia a utilização de um recurso seus resultados crescem a taxas decrescentes.

Assim o aumento da disponibilidade de recursos de saúde em países em desenvolvimento apresentam taxas de retorno mais significativa sobre o crescimento da riqueza nacional. Países que ainda presenciam situaçóes de extrema pobreza ou pós-guerra teriam um crescimento ainda mais amplo da riqueza nacional se houver um implemento de 
recursos de saúde, isso é relatado no trabalho de Bleakley (2007) que analisou campanhas de erradicação contra doenças parasitárias como a ancilostomíase em países da América Latina e percebeu que coortes expostas a essas campanhas, como crianças, apresentaram maior produtividade do trabalho quando entraram no mercado de trabalho.

Ainda nesta linha para reafirmar o impacto da saúde no crescimento da riqueza e do bem-estar a nível nacional trabalhos de cunho micro econômicos que apontam para o aumento da produtividade do trabalho em ambientes de mais disponibilidade de serviços e produtos de saúde, são exemplos destes gênero os trabalhos de Strauss e Thomas (1998); Behrman e Rosenzweig (2001); Thomas e Frankenberg (2002); Suhrcke (2005); Ruger $e$ t al (2006); Schultz (2002); Miguel e Kremer (2004); Bleakley (2006) (esses três últimos utilizaram estudos de coorte). A abordagem microeconômica e o detalhamento a respeito dos trabalhos acima citados serão abordados na próxima seçáo.

\section{A abordagem microeconômica da saúde.}

A abordagem microeconômica da saúde é aquela que compreende as relaçóes internas das entidades, aborda o consumidor enquanto indivíduo e o setor produtivo empresa à empresa. Utiliza-se de dados individuais e domésticos, e busca-se compreender as relaçóes de forma desagregada.

A abordagem microeconômica da saúde busca evidências da relação entre ambos os campos, utilizando-se de variáveis como: salários e rendimentos, quantidade de horas trabalhadas, participação da força de trabalho, aposentadoria precoce, decisão de poupar, e oferta de trabalho de aqueles dando assistência a membros do agregado familiar doente (SUHRCKE, 2005).

As metodologias mais amplamente utilizadas são os estudos experimentais ou quase experimentais, que tem como intuito fornecer evidências científicas sobre a relação causal entre a saúde e o desfecho estudado. (Hussain, 2009) Há também diversos estudos observacionais, que normalmente são baseados em dados de pesquisa e são estimados em conjun to com um modelo de comportamento que visa proporcionar um argumento plausível para interpretar a evidência de um quadro causal. (THOMAS e FRANKENBERG, 2002). Exemplos, de abordagens microeconômicas em contexto diferente podem ser encontrados em Strauss e Thomas (1998), Behrman e Rosenzweig (2001), Thomas e Frankenberg (2002), Schultz (2002), Miguel e Kremer (2004), Suhrcke (2005), Ruger (2006).

Vários desses trabalhos tem como objeto a relação entre a deficiência de macro ou micro nutrientes e a produtividade do trabalho. Por exemplo, Thomas e Frankenberg (2002) fizeram um levantamento de estudos que examinaram o efeito causal da deficiência de ferro na capacidade de trabalho por meio da comparação da produção e da produtividade do grupo de tratamento em comparaçáo a um grupo de controle, os estudos levantados mostram que a deficiência de ferro afeta a capacidade aeróbica do indivíduo, resistência, eficiência energética, consequentemente sua produtividade.

Outro exemplo deste gênero, que no entanto, quantificou os resultados obtidos na diferença de produtividade foi, a pesquisa de Li et al. (1994) em que se realizou um estudo de controle de tratamento randomizado com 80 chinesas trabalhadoras de 
moinhos de algodão ferro-deficientes, não grávidas, e descobriu que os trabalhadores que receberam suplementação de ferro durante 12 semanas apresentaram um aumento de 5\% na produtividade em relação aos indivíduos do grupo controle que receberam placebo. Outros trabalhos analisaram a relaçấo entre o acréscimo de calorias e a produtividade dos indivíduos, como por exemplo, Strauss (1986); Sahn e Alderman (1988); Thomas e Strauss (1997) e Fuentes et al. (2001).

Outros experimentos mostram que há vários outros campos dentro das ciências da saúde para além da nutrição que tem um impacto causal sobre a prosperidade econômica. Por exemplo, Moffett et al. (1999) desenvolveram um estudo com homens com dor nas costas designados aleatoriamente para um programa de exercícios (o grupo de tratamento) ou para a gestão de cuidados primários usual (grupo controle). Depois de um ano, os participantes do grupo de tratamento apresentavam menos dias de absenteísmo em comparação ao grupo controle. Mais exemplos podem ser vistos nos trabalhos de Newhouse (1993), que incluem mudanças no preço dos cuidados de saúde, Dow et al. (2001) e as variaçóes nos preços dos serviços de saúde e Gruber e Hanratti (1995), que incluíram as diferenças entre sistemas de seguro de saúde.

Diversos e variados instrumentos utilizados na abordagem microeconômica da saúde apontaram para o impacto positivo desse vetor na geração de riqueza. As análises que abordam a redução dos ganhos auferidos em decorrência de problemas de saúde são abundantes na literatura, e estendem-se por décadas, abordando assim diferentes fases do sistema capitalista. Tem-se como exemplo, os trabalhos de Mincer (1958), Schultz (2002), Becker (1962), Bem-Porath (1967) Grossman (1997), Luft (1975), Bartel e Taubman (1979), Chirikos e Nestel, (1985), Gustman e Steimeir, (1986), Hansen (2000), Andrén e Palmer (2001), Contoyannis e Rise (2001), Gambin (2004), Pelkowaski e Berger (2004).

Em particular, neste último trabalho citado, Grossman (1997) elaborou um modelo de demanda para a saúde, em que trabalhou a complexa relaçáo entre o tempo de trabalho, histórico de doenças e o salário. Já Andrén e Palmer (2001), estimaram os ganhos anuais, utilizando uma equação para o salário por hora, e encontraram indícios de que as pessoas que são saudáveis no ano em curso, mas que tiveram a doenças nos últimos cinco anos têm rendimentos menores nos anos seguintes do que pessoas sem históricos de doença. Estudos semelhantes foram desenvolvidos por Gustman e Steinmeir (1986), Hansen (2000), Contoyannis e Rise (2001), Gambin (2004), Pelkowaski e Berger (2004).

Em nível microeconômico, vários estudos apontam principalmente o absenteísmo, a baixa produtividade e a saída do indivíduo do mercado de trabalho como principais aspectos da saúde que geram impactos, nestes casos, negativos sobre o crescimento e desenvolvimento econômico. Chirikos e Nestel (1985) afirmam que problemas de saúde afetam a oferta de trabalho, e estimaram a cadeia de efeitos que liga os problemas de saúde à pobreza e à menor quantidade de horas trabalhadas por ano.

Outra variável sempre empregada em modelos que tentam explicar o crescimento e o desenvolvimento econômico é a educação. O nível educacional da população está presente em diversos modelos, porém é preciso ressaltar a relação entre a educação e a saúde de um indivíduo. Há várias formas de se explicar a associação entre esses dois fatores, entre eles, a relação causal que vai da educação para a saúde, em que o indivíduo com o maior nível 
educacional terá mais subsídios para a tomada de decisóes, tais como a escolha de medidas preventivas que promovam a sua saúde e diminuam as chances de doença, menor exposição a fatores de risco evitáveis. Exemplos de trabalhos que abordam essa relação causal são: Grossman e Kaestner (1997), Grossman (2004), Lleras-Muney (2005). Quanto à relação causal oposta, que vai da saúde para a educação, tem-se um indivíduo com uma melhor condição de saúde, o que melhora ainda sua capacidade cognitiva, com menor absenteísmo (BLEAKLEY, 2007).

A relação de interdependência saúde-educação ainda pode ser vista de diversas outras formas, as chances de crianças com uma saúde melhor chegar a níveis de educação mais elevados e, consequentemente, serem mais produtivos no futuro são maiores. Ainda na mesma linha, os indivíduos mais saudáveis têm uma expectativa de vida útil mais longa, assim, teriam maiores incentivos para investir em educação, visto que poderiam beneficiarse por mais tempo desse investimento (KALEMLI-OZCAN et al., 2000). Outra forma de observar os benefícios da saúde para elevação dos níveis educacionais da população é na relação entre a escolaridade de crianças órfâs e com pais vivos, na qual crianças órfâs tem um nível de escolaridade inferior. A melhoria nos níveis de saúde reduz a mortalidade de adultos que por sua vez reduz o número de crianças órfẫs (CASE et al., 2004).

Outra perspectiva é quanto à taxa de poupança, visto que a taxa de investimento depende da taxa de poupança de uma sociedade. Um indivíduo com uma expectativa de vida maior seria compelido a ter uma maior taxa de poupança, planejando uma vida mais longa e velhice saudável. A ideia de planejamento e, consequentemente, poupar para a aposentadoria, seria esperada para ocorrer somente quando as taxas de mortalidade tornassem-se baixas o suficiente para que a aposentadoria fosse uma perspectiva realista (SMITH, 1999). Outra pesquisa, desenvolvida por Kinugasa e Mason (2007) avalia os efeitos da mudança da longevidade dos adultos sobre a taxa de poupança nacional, utilizando dados históricos e dados de painel internacionais, e um modelo de geração de sobreposição; e considera que o aumento da esperança de vida de adultos tem um efeito grande e estatisticamente significativo sobre a poupança agregada. Da mesma forma, Lee, Mason e Miller (2000) acompanharam o ciclo de vida padrão no contexto da transição demográfica em Taiwan e obtiveram conclusóes semelhantes.

Entendendo a abordagem macroeconômica como o agregado das relaçóes microeconômicas, pode-se inferir que há uma relação micro e macro entre a saúde da população e seu potencial de crescimento e desenvolvimento econômico. Todas as relaçóes aqui apresentadas, além de seus efeitos estritos, gerariam externalidades positivas, que não são facilmente percebidas seja na abordagem micro ou macroeconômica.

As limitaçóes da abordagem microeconômica também precisam ser reconhecidas, assim é preciso lembrar que mesmo que todos os indivíduos estivessem plenamente saudáveis, os demais fatores de produção ainda continuariam limitados, cerceando assim, parte do potencial de crescimento de uma sociedade. No entanto, isso não invalida à lógica aqui apresentada, visto que, ceteris paribus os demais fatores, uma elevação no nível de saúde de uma população levaria a um maior potencial de geração de riqueza. 


\section{A evoluçáo do desenvolvimento econômico e da saúde}

Ao longo dos últimos dois séculos as ciências da saúde vivenciaram uma grande expansão em suas áreas de pesquisa, (HUSSAIN, 2009) muitos novos produtos e serviços foram lançados no mercado e impactaram significativamente na expectativa de vida, assim como no bem-estar, da população mundial. No entanto, a disponibilidade e o acesso a essas tecnologias se dá de forma heterogênea, entre diferentes países. Essa percepção levou ao surgimento de diversas pesquisas que sobrepóem os resultados econômicos de diferentes nações, desenvolvidas e em desenvolvimento, aos fatores de saúde disponíveis a essas populaçóes ao longo do tempo. Busca-se analisar o histórico de morbidade e mortalidade e as diferentes causas, entre diferentes países, assim como, dentro dos países, e com a sobreposição dessas informaçóes, tenta-se compreender as tendências observadas.

Como exemplo deste gênero de pesquisa tem-se Fogel (1994, 1997), que analisou os dados para os últimos 200 anos (1780-1980) para o Reino Unido, desenvolvendo uma pesquisa na qual cruzavam-se os dados existentes sobre a ingestão média de calorias, oferta de alimentos, altura e peso médio da população, concluindo que, o aumento da oferta de alimentos fez crescer a produtividade média da população, contribuindo assim para o aumento do PIB nacional. Outro vetor importante é a redução na morbidade e mortalidade, que apresentou tendência contrária à taxa de crescimento da renda per capita. Assim, percebe-se que o aumento da ingestáo de calorias náo ampliou apenas a produtividade do trabalhador, mas também, sua expectativa de vida, tendo um duplo efeito positivo, visto que, o trabalhador além de mais produtivo permanece por mais tempo em idade ativa.

As estimativas mostram que com a maior oferta de alimentos, a população mais carente do país, até então a que apresentava as maiores taxas de morbidade e mortalidade, foi incorporada à força de trabalho e teria contribuído com $0,11 \%$ da taxa histórica de crescimento da renda per capita do Reino Unido, que no período analisado foi de $1,15 \%$ (FOGEL, 1997).

Outro trabalho deste gênero foi desenvolvido por Cutler et al. (2006), que cruzaram os dados de uma série de países, identificando no histórico de mortalidade pontos críticos nos quais ocorreram mudanças tecnológicas ou intervençóes do estado, como nas primeiras décadas do século XX, quando se iniciaram políticas para a estruturação de sistemas de fornecimento de agua potável, remoção de resíduos e conscientização pública acerca dos hábitos de higiene pessoal (CUTLER et al. 2006).

Usando de uma lógica semelhante, Arora (2001) analisou a influência da saúde, usando cinco medidas de saúde a longo prazo, na trajetória de crescimento de dez países industrializados ao longo de 100 anos, e concluiu que as mudanças na saúde aumentaram seu ritmo de crescimento de $30 \%$ a $40 \%$, alterando assim, permanentemente a inclinação da curva histórica de crescimento.

Um dos mais relevantes impactos da saúde sobre o crescimento decorre da redução da mortalidade e consequente mudança da estrutura demográfica das naçóes, que acarreta uma alteração na relação entre indivíduos ativos e inativos, em termos econômicos.

Mudanças demográficas ocorrem tanto por alteraçóes nas taxas de mortalidade como de fertilidade da população, como por ondas migratórias. As diferentes causas para 
mudanças demográficas significativas trazem consigo resultados diferentes, alterando a relação de indivíduos ativos e inativos, a composição etária ou a densidade populacional.

A saúde tende a promover simultaneamente a redução da taxa de mortalidade e o aumento da taxa de fertilidade. No entanto, historicamente, nas últimas décadas algumas nações desenvolvidas apresentam uma redução voluntária da taxa de fertilidade em decorrência da oferta de meios contraceptivos mais simples, efetivos e menos custosos, assim como do empoderamento da mulher na sociedade.

Além da ampliação dos direitos das mulheres para decidirem sê e quando terão filhos, outras mudanças comportamentais aconteceram, como por exemplo em decorrência do surgimento de serviços e produtos de saúde. Podem ser observadas nos padróes de poupança, participação da força de trabalho, investimento e elevação no nível de escolaridade. A inclusão dessas variáveis enriqueceu a discussão da relação saúde-riqueza (HUSSAIN, 2009). Como afirmado acima, historicamente, todas as mudanças tendiam a promover o aumento da densidade demográfica, que impactava positivamente no crescimento econômico das nações, pois fornecia um crescente mercado de mão de obra, assim como um mercado consumidor. No entanto, nem todos os autores concordam que essa tendência possa se perpetuar indefinidamente. Assim como Thomas Malthus (1826), vários autores ressalvam que nem todos os insumos produtivos podem crescer junto à população e assim fornecer os bens e serviços demandados. A limitação de fatores naturais seria um entrave ao crescimento econômico e agravar-se-ia pelo constante crescimento populacional, Coale e Hoover (1958) retomaram essas discussóes.

Por outro lado, há os autores como Birdsall e Sinding, (2001) e Kelley e Schmidt (2001) que defendem que o crescimento populacional gera efeitos compensadores e assim geram novos elementos, como o avanço tecnológico relevado por Malthus, que seriam capazes de dar sustentabilidade ao crescimento demográfico.

Foley (2000), afirma que o crescimento demográfico pode ser sustentado ao se adotar largamente a divisão do trabalho, seguindo uma visão Smithiana, o autor afirma que a eficiência da divisão do trabalho seria capaz de gerar um padrão de vida satisfatório, contrariando as ideias de cunho Malthusiano, que preveem um baixo padrão de qualidade de vida quanto maior for a população.

Em consequências dessas alteraçóes médicas, nutricionais e culturais, a estrutura demográfica de diversos países tem melhorado, percebendo-se uma redução tanto da mortalidade como da fertilidade, e um aumento da expectativa de vida e diminuição da morbidade. Assim, houve uma mudança importante na distribuição etária dessas populaçóes, sobre as quais Birdsall e Sinding (2001) afirmam que:

(...) embora as mudanças tenham acontecido lentamente quando avaliadas academicamente, elas têm sido incrivelmente rápido em termos históricos, e altamente diferenciadas entre os países, o que torna possível avaliar o impacto dessas mudanças no tempo e entre países (BIRDSALL e SINDING, p.04, 2001. tradução própria). Grande parte dessas mudanças aconteceu em tempos relativamente recentes, assim além das tendências generalistas, esses movimentos proveram dados suficientemente completos para permitir sua análise empirista mais formal, em consonância com as premissas básicas do método cientifico. Tem-se como exemplo deste gênero de pesquisa os trabalhos de Bongaarts (2001), Birdsall e Sinding 
Os autores Bloom, Williamson e Canning afirmam que o crescimento econômico da Ásia oriental foi concomitante à expansão demográfica na região no período 1950-2000. Entre 1965 e 1990 a população em idade ativa na região cresceu quase quatro vezes mais rápido do que a população dependente. Na mesma linha, outros trabalhos afirmam que o crescimento populacional foi responsável por um terço do crescimento econômico da Ásia Oriental durante o período (BLOOM E WILLIAMSON, 1998).

Usando-se da mesma lógica, os autores analisaram os efeitos da legalização de contraceptivos na Irlanda em 1979, na década seguinte o país apresentou uma reduçáo significativa na taxa de natalidade, no mesmo período também se observou uma redução no número de jovens dependentes químicos e um aumento dos jovens no mercado de trabalho. Na década de 1990 o número de dependentes químicos na Irlanda já era inferior ao registrado no Reino Unido. Assim, pode-se relacionar a mudança demográfica da Irlanda a sua trajetória recente de desenvolvimento (BLOOM, CANNING e SERVILLA, 2003). A redução da expansão demográfica aliada à aceleração do crescimento econômico do país promoveu uma inversão do processo migratório na região, tornando a Irlanda atrativa aos imigrantes, sobretudo aos emigrantes que haviam deixado o país em anos anteriores.

\section{Estudos desenvolvidos na América Latina usando a abordagem econômica da saúde.}

Quando se pensa em políticas e teorias econômicas acerca do desenvolvimento, a América Latina é um campo vasto. Diversos pesquisadores renomados e grupos de pesquisas influentes nasceram na regiáo com o intuito de criar um contraponto ao mainstream de teorias econômicas que náo abarcavam a realidade latino-americana. $\mathrm{O}$ exemplo mais famoso é a CEPAL - Comissão Econômica para a América Latina e o Caribe, que reuniu pensadores de vários países da América Latina e produziu trabalhos que até hoje influenciam na tomada de decisão e na construção de políticas.

Nesta seção do trabalho reuniu-se algumas pesquisas que foram desenvolvidos com base na abordagem econômica da saúde, em países da América latina. O primeiro estudo buscou analisar o impacto do investimento em saúde no crescimento econômico e no aumento do bem estar da população. Fomentados pelo Banco Interamericano de Desenvolvimento, foi desenvolvido nos diversos centros de pesquisa da Organização Panamericana de Saúde, em vários países da América latina, um resumo dos resultados pode ser encontrado em Granados 2002, p.140.

Um trabalho realizado por Robles e Galanis (2002) no México, analisou a relação saúde, nutrição e salários, utilizando o número de mulheres adultas entrantes no mercado de trabalho e sua idade de menarca. Os resultados mostraram uma redução na variância da idade de menarca das jovens nos últimos 40 anos, tal fato acompanha o ritmo de urbanizaçáo do país, ou seja, essa redução pode ser causada pelo acesso a serviços públicos, principalmente aos de saúde e saneamento básico, assim como um melhor acesso à alimentação. 
Segundo esse estudo, a qualidade na alimentação e o acesso a serviços básicos de saúde alteraram a idade média de ocorrência da menarca na população mexicana e isso impactou positivamente à produtividade das mulheres no mercado de trabalho.

Outro trabalho desenvolvido por Sachs (2002) no Peru, analisa as relaçóes de gênero e sua distribuição espacial no país, soma-se ao conjunto de trabalhos que sustentam a ideia de que a saúde é componente do capital humano, que influência na capacidade do indivíduo de gerar renda no presente e de promover o aumento sustentado de sua renda no futuro.

Outro trabalho desenvolvido por Fuentes, Conyer e Fernández (2001) na América latina compilou os resultados de outros trabalhos semelhantes em oito países. Todos eles mostram uma grande disparidade na distribuição de renda e nos níveis de saúde da população desses países. Os dados mostram que a população carente é também a mais vulnerável, os resultados apontam a ampliação dos serviços públicos de saúde como uma alternativa para a solução deste problema, sobretudo para populações afastadas dos centros urbanos, como agricultores e populaçôes indígenas. Assim seria o sistema público de saúde uma alternativa para iniciar essa ruptura na desigualdade.

Os trabalhos aqui citados foram selecionados por apresentar uma abordagem estatística, utilizando-se de uma ampla base de dados, alguns observando a distribuição espacial, outros a questão de gênero, premissas e métodos semelhantes aos desenvolvidos nessa dissertaçáo, no entanto, existem muitos trabalhos desenvolvidos acerca do tema na América Latina. A Organização Pan-Americana de Saúde publicou em 2003 um trabalho reunindo o conjunto de todos os trabalhos desenvolvidos na América latina, com apoio da instituição, chamado Invertir en salud: beneficios sociales e económicos. Mais trabalhos podem ser encontrados na Revista Panamericana de saúde pública.

Pode-se observar que o desenvolvimento regional e local tem relação direta com a economia da saúde, que por sua vez está intimamente atrelada à gestão da saúde. No próximo capítulo será abordado o tema da gestão estratégica em saúde e como essa forma de gestão pode ampliar a eficiência do sistema para alcançar seus objetivos primários, ampliação dos níveis de saúde da população, assim como, alcançar objetivos mais estruturados a partir da integração do sistema de saúde com demais áreas da gestão pública.

\section{METODOLOGIA}

Trata-se de uma pesquisa que adotou o método econométrico, portanto quantitativo e causau, para a investigar a relação entre saúde pública no desenvolvimento sócio econômico nos municípios do Estado do Paraná. Foi utilizado um conjunto de dados referente ao sistema de saúde pública, agregados por municípios, e indicadores de desenvolvimento e de riqueza. Elaborou-se um modelo cujo intuito é verificar se há um impacto positivo do sistema de saúde pública na trajetória de desenvolvimento do estado, visto que a saúde da população tende a refletir no sistema produtivo e nos padróes de consumo.

Os dados foram agregados a nível municipal, pois, a forma de gestão decentralizada adotada pelo SUS permite também que os agentes e gestores locais tenham maior autonomia, dando assim pluralidade quando se observa o sistema ao nível dos municípios. 
Não existe consenso a respeito de um modelo definitivo que relacione a estrutura de saúde disponível, pública ou privada, e seus determinantes sobre o desenvolvimento econômico e social. Nesse caso optou-se pelo método de dados em painel (combinação de dados de corte transversal com séries temporais), pois, esse método consegue controlar o efeito de variáveis omitidas, mesmo sem observá-las de fato, através do estudo de variações na variável dependente ao longo do tempo, se forem constantes (NAKAMURA et al. 2007 p.79). Consistente com o fato de os dados serem referentes às mesmas unidades (municípios) e de recorte longitudinal, náo podendo-se assumir que as observaçóes sejam independentes para a finalidade de análise econométrica.

Quando se adota a metodologia dos dados em painel há duas técnicas de estimação, efeitos fixos ou efeitos aleatórios, segundo Wooldridge (2010 p.449), ambas servem para estimar modelos de efeitos não observados de dados em painel.

Por meio da análise da bibliografia sobre o tema pesquisado elegeu-se as variáveis explicativas, aquelas que tem potencial para interferir nas explicadas. E as variáveis explicadas como sendo passíveis de mudança e que representam o desenvolvimento em suas duas vertentes, estritamente econômica e sócio econômica. A tabela 1 a seguir mostra o conjunto de variáveis selecionadas para o modelo que será aplicado no trabalho.

Tabela 1 - Relação de variáveis utilizadas nos modelos.

\begin{tabular}{|c|c|c|}
\hline Variáveis explicativas & Unidade & Fontes \\
\hline $\begin{array}{l}\text { Despesa total da saúde no município } \\
\text { (per capita) }\end{array}$ & Reais $(\mathrm{R} \$)$ & $\begin{array}{l}\text { Sistema de Informaçóes sobre } \\
\text { Orçamentos Públicos em Saúde } \\
\text { (SIOPS) }\end{array}$ \\
\hline $\begin{array}{l}\text { Despesa com recursos próprios } \\
\text { (per capita) }\end{array}$ & Reais $(\mathrm{R} \$)$ & $\begin{array}{l}\text { Sistema de Informaçóes sobre } \\
\text { Orçamentos Públicos em Saúde } \\
\text { (SIOPS) }\end{array}$ \\
\hline Despesa com pessoal (per capita) & Reais $(\mathrm{R} \$)$ & $\begin{array}{l}\text { Sistema de Informaçóes sobre } \\
\text { Orçamentos Públicos em Saúde } \\
\text { (SIOPS) }\end{array}$ \\
\hline $\begin{array}{l}\text { Despesa com saúde complementar } \\
\text { em } \%\end{array}$ & $\begin{array}{l}\text { \% Proporção da despesa } \\
\text { total }\end{array}$ & DATASus \\
\hline $\begin{array}{l}\text { Cobertura do programa Estratégia } \\
\text { Saúde da Família (ESF) }\end{array}$ & $\begin{array}{l}\text { \% da área atendida no } \\
\text { município }\end{array}$ & $\begin{array}{l}\text { Departamento de atenção básica } \\
\text { (DAB) }\end{array}$ \\
\hline No de agente comunitários da Saúde & Por 100 mil habitantes & $\begin{array}{l}\text { Departamento de atenção básica } \\
\text { (DAB) }\end{array}$ \\
\hline \multicolumn{3}{|l|}{ Variáveis explicadas } \\
\hline PIB per capita & Reais (R\$) & IBGE \\
\hline $\begin{array}{l}\text { Índice FIRJAN de Desenvolvimento } \\
\text { Municipal (IFDM) }\end{array}$ & Índice $(0-1)$ & \begin{tabular}{|l|} 
Federação das Indústrias do Estado do \\
Rio de Janeiro \\
\end{tabular} \\
\hline $\begin{array}{l}\text { Índice IPARDES de desempenho } \\
\text { Municipal (IPDM) }\end{array}$ & Índice $(0-1)$ & \begin{tabular}{|l} 
Instituto Paranaense de \\
Desenvolvimento Econômico e Social
\end{tabular} \\
\hline
\end{tabular}

Fonte: Elaborado pelo Autor, 2020.

Os dados utilizados são referentes ao período de 2000 a 2014, o recorte temporal ocorre em função da disponibilidade do conjunto, embora houvesse séries mais recentes para algumas variáveis optou-se por compor um painel balanceado, ou seja, com todas 
as variáveis possuindo observações para todos os períodos analisados. Não foi efetuado o deflacionamento das variáveis mensuradas em valores monetários, devido à natureza do instrumental estatístico que foi adotada por esse autor e conforme Gujarati (2006), para os dados em painel é desnecessário deflacionar, pois, este relaciona as variáveis dependentes e independentes por ano.

Os dados das variáveis explicativas foram selecionados de forma a fornecerem um panorama do sistema público de saúde em cada município. O valor total do orçamento com saúde apresenta, por uma perspectiva pecuniária, a evolução do sistema, seu porte e nível de atividades. A despesa com pessoal é uma variável próxi utilizada para mensurar o capital humano disponível. A abrangência do programa ESF reflete o desenvolvimento de políticas de promoção à saúde, este é importante, pois, os outros dados geralmente refletem um sistema mais voltado para o tratamento de enfermidades.

Já os índices IFDM e IPDM são variáveis que visam mensurar o nível de desenvolvimento econômico e social do município, para isso, será utilizado também o PIB per capita medido em reais, que demonstra o nível de riqueza relativa disponível em cada município, entendido no trabalho como uma forma de mensurar o desenvolvimento econômico.

A adoção desses índices se dá, pois ambos englobam variáveis em seus cálculos que não são mensuradas quando se adota apenas o PIB per capita como próxi do desenvolvimento, essa abrangência faz-se necessária quando se entende o desenvolvimento como implemento da qualidade de vida da população.

\section{Coleta e tratamento dos dados}

Os dados foram coletados das fontes indicadas na Tabela 1 , sendo feito o agrupamento dos dados seguindo a lógica requerida pelo modelo de análise, Panel data, assim, após a coleta, os dados foram empilhados, formando uma coluna para cada variável, mantido os dados referentes à cada municípios em ordem cronológica e criou-se uma coluna com um identificador numérico para cada município.

Posteriormente, fez-se importação dos dados para o software Stata 12. Os dados que não representam valores percentuais foram logaritimizados para permitir uma análise de elasticidade, assim criou-se usando o Stata 12, cinco novas variáveis, sendo elas: Log do Pib per capita, Log do IPDM, Log das Despesas totais, Log das despesas totais per capita, Log das Despesas totais com recursos próprios, Log das Despesas com pessoal, Log do número de ACS implantados para cada 100 mil habitantes. Essas variáveis substituíram as originais no modelo, permitindo assim, uma análise de elasticidade, ou seja, o quanto impacta, em percentual, na variável explicada, uma variação de $1 \%$ na variável explicativa.

Os modelos iniciais são dado por:

$$
\begin{gathered}
\log (P I B p c)_{i t}=\log (D \cdot \operatorname{totpc})_{i t}+\log (D \cdot R \cdot P p c)_{i t}+\log (D \cdot \text { Pessoalpc })_{i t}+(D \cdot S c o m p)_{i t} \\
+\log (N A C)_{i t}+(E S F)_{i t}+u_{i t}
\end{gathered}
$$

Onde: log: é o logaritmo na base 10, $i$ : é o município, $t$ : é o ano.

D. Totpc: Despesa total da saúde no município (per capita) 
D.R.Ppc: Despesa com recursos próprios (per capita)

D.Pessoalpc: Despesa com pessoal (per capita)

DScomp: Despesa com Saúde complementar

$N A C$ : é o número de agentes comunitários por $100 \mathrm{mil}$

$E S F$ : é o nível de cobertura programa saúde da família em percentual

PIBpc: é o PIB per capita

$u$ : é o termo de erro

Os demais modelos seguem a mesma lógica, alterando somente a forma de mensurar o nível desenvolvimento municipal, sendo apresentados a seguir.

$$
\begin{aligned}
& \log (I P D M)_{i t}=\log (\text { D.totpc })_{i t}+\log (\text { D.R.Ppc })_{i t}+\log (\text { D. Pessoalpc })_{i t}+(\text { D.Scomp })_{i t} \\
& +\log (N A C)_{i t}+(E S F)_{i t}+u_{i t}
\end{aligned}
$$

No qual IPDM é o Índice IPARDES de Desenvolvimento Municipal.

$$
\begin{gathered}
\log (\text { IFDM })_{i t}=\log (\text { D.totpc })_{i t}+\log (\text { D.R.Ppc })_{i t}+\log (\text { D.Pessoalpc })_{i t}+(D . \text { Scomp })_{i t} \\
+\log (N A C)_{i t}+(E S F)_{i t}+u_{i t}
\end{gathered}
$$

No qual IFDM é o Índice FIRJAM de Desenvolvimento Municipal. Este modelo foi removido durante a análise devido à alta correlação apresentada com o IPDM, o resultado e explicação dessa remoção são apresentados na seção seguinte deste trabalho.

\section{RESULTADOS E DISCUSSÃO}

A análise descritiva do IFDM para os 399 municípios do estado do Paraná demostram uma tendência de aumento do indicador aliado a uma tendência de redução do desvio padrão. A soma dessas duas tendências demonstra que a qualidade de vida da população paranaense tem melhorado no período analisado, e que as discrepâncias regionais têm diminuído. Em outras palavras, as três dimensões socioeconômicas avaliadas pela FIRJAM mostraram melhoras em seus indicadores, ou seja, há mais emprego e renda, melhores indicadores educacionais e de saúde para os municípios avaliados. A reduçáo do desvio padrão demonstra uma aproximação, ou seja, um nivelamento entre os municípios, que demonstram uma maior equidade entre esses.

Considerando a natureza do modelo econométrico foi feito uma análise de correlação entre ambos os índices com intuito de verificar se estes possuíam diferença estatística relevante. $\mathrm{O}$ resultado é apresentado na Tabela 2 abaixo.

Tabela 2 - Correlação IFDM-IPDM, dados relativo ao período 2007 - 2011.

\begin{tabular}{ll|l}
\hline Correlação & IPDM & IFDM \\
\hline IPDM & 1.0 & \\
\hline IFDM & 0.799 & 1.0 \\
\hline N. de observaçóes: 1992 & & \\
\hline
\end{tabular}

Fonte: Elaborado pelo autor, 2020. 
Sendo o resultado uma correlação forte, ou seja, superior a 0,7 (FIQUEIREDO e SILVA, 2009) optou-se por abdicar de um dos indicadores, pois, ambos tenderiam ao mesmo resultado, neste caso a escolha foi manter o indicador IPDM, por sua maior aderência à realidade paranaense, pois, foi desenvolvido por uma instituição paranaense visando a realidade e especificidades dessa população.

\section{Modelo cuja variável dependente é o PIB per capita.}

Utilizando o PIB per capita como variável independente, chegou-se a um modelo de efeitos fixos para as unidades e para o tempo com erros robustos, esse modelo apresenta cinco variáveis significativas. No modelo inicial foi identificado problemas de heterocedasticidade, sendo a estatística do teste de Wooldridge, F=584,6 e a significância 0,0. Fato já esperado visto que, adotando se o PIB como variável explicada, e sendo este composto pela soma de todas as atividades econômicas realizadas no período, a utilização de variáveis explicativas relacionadas unicamente à saúde pública é incapaz de prover explicação suficiente para a variável explicada (PIB). O problema da heterocedasticidade foi resolvido utilizando o comando > robust < que gera a regressão com erros padráo robusto, sendo eficiente quando os erros não seguem uma distribuição normal (JANN, 2012).

Em um modelo com erros padrão robusto é calculado um estimador de variância robusta baseada em uma lista de variáveis, neste caso, as variáveis explicativas, das pontuaçóes de nível equação e uma matriz de covariância. Ela produz estimadores para dados comuns (cada observação independente), agrupados de dados (dados não independentes dentro dos grupos, mas independentes entre grupos), e dados de inquéritos complexos de um estágio de amostragem estratificada por conglomerados. (STATA 13, 2014)

Fora escolhido o modelo para efeitos fixos após comparar os resultados dos testes de especificação de Chow, Hausmann e Breuscho-Pagan. Em todos os testes rejeitou-se a hipótese nula a um índice de confiança de 5\%. O modelo é apresentado na Tabela 3 a seguir.

Tabela 3 - Resumo dos resultados obtidos no modelo de efeitos fixos para as unidades e para o tempo, para o $\log \mathrm{PIB}$, com erros robustos.

\begin{tabular}{llcc}
\hline Variável & Coeficientes & $\mathrm{p}$ Valor & Erro padráo robusto \\
\hline Log.Desp. total per capita & 0,309 & 0,0 & 0,03 \\
\hline Log.Desp. Recursos próprios & 0,302 & 0,0 & 0,031 \\
\hline Log.Desp. Pessoal & - & & - \\
\hline Log. No ACS & $-0,102$ & 0,04 & 0,05 \\
\hline Log. Saúde Complementar & 0,001 & 0,0 & 0,0003 \\
\hline Cobertura ESF & 0,001 & 0,009 & 0,0004 \\
\hline F & 170,71 & 0,0 & \\
\hline$R^{2}$ & 0,4634 & & \\
\hline
\end{tabular}

Fonte: Elaborado pelo autor, 2020. 
O modelo, que utiliza como variável explicada o PIB per capita, foi o que apresentou o melhor ajuste. Esse modelo possui cinco variáveis estatisticamente significativas, sendo elas: a) Despesas totais per capita; b) Despesas com recursos próprios; c) Número de agentes comunitários de saúde; d) Percentual da despesa total utilizado na saúde complementar e; e) Cobertura do programa ESF.

O modelo é de efeitos fixos tanto para as unidades, municípios, como para o tempo. Tal modelo foi selecionado tomando como norteador os testes de Chow, Hausmann e Breusch-Pagan. Em decorrência da adoção de um modelo de erros robustos foi preciso utilizar o teste de Hausman, adaptado para erro robusto, desenvolvido por Wooldridge, tal como apresentado por Cameron e Trivedi (2010, p.262). Sendo este um modelo de efeito fixo os coeficientes e intercepto é o mesmo para todas as unidades e ao longo do tempo e, assim sendo, representam o comportamento médio da variável para os 399 municípios ao longo dos cinco anos pesquisados neste trabalho.

O modelo de efeitos fixos é o mais recomendável, segundo Gujarati (2006), quando as unidades apresentam certa similitude, neste caso causada pela estrutura legal a que tem que se submeter a administração municipal. O mesmo vale para a constância temporal, aliado ao fato de que nos cinco anos de análise, houve uma eleição municipal no primeiro ano, sendo assim os quatro anos seguintes que compuseram o período de análise tendem, respeitando à cultura política brasileira, a manter um programa de gestão.

Apenas a variável - número de agentes comunitários de saúde - apresentou-se inversamente relacionada ao PIB per capita, todos os demais coeficientes apresentam sinais positivos, ou seja, as variáveis estão diretamente relacionadas. Implementos no sistema de saúde tendem a elevar o PIB per capita municipal.

O maior efeito foi apresentado pela variável - despesas totais per capita-, que representa todo o aporte de recursos feito dentro do território municipal, independente da origem dos recursos, dividido pelo número de habitantes. O coeficiente relacionado a esta variável apresentou valor igual a 0,309 o que, indicando que um aumento de $1 \%$ nas despesas totais per capita que geram um aumento no PIB per capita de $0.3 \%$, ou seja, os investimentos em saúde de forma geral. Essa variável não apresenta discricionariedade em relaçáo à origem ou destino dos valores aplicados, estâo em consonância com a literatura, que afirma que investimentos em saúde levam a uma elevação do produto, assim como afirma Granados (2002), ao elaborar uma estrutura de encadeamento lógico entre os investimentos em saúde e o aumento do produto. Nessa mesma linha seguem os trabalhos Caselli, Esquivel e Lefort (1996); Hamoudi e Sachs (1999); Gallup e Sachs (2000), que desenvolveram análises econométricas e chegaram a evidencias de que sistemas de saúde públicos impactam positivamente sobre o crescimento da riqueza nacional.

Essa análise de elasticidade é possível, pois, todas as variáveis que não eram originalmente apresentadas em percentual foram logaritimizadas. É preciso ressaltar que sendo este um modelo de efeitos fixos os indicadores representam o comportamento médio de todas as unidades ao longo do tempo, como já mencionado anteriormente. Essas duas características se estendem a todas as demais variáveis do modelo. 
A segunda variável com o maior coeficiente foi - as Despesas com recursos próprios, cujo coeficiente é 0,302 - mostra que um aumento em $1 \%$ nos dispêndios com mão de obra especializada em saúde, gera um implemento de $0.3 \%$ no PIB per capita. Essa variável foi escolhida como proxy da gestão local, pois é nesta parte dos recursos que a gestão municipal possui a maior autonomia de decisão sobre sua alocação, estando assim em consonância com as teorias de desenvolvimento regional e local, como preconizam os autores Boisier (1988), Putnam (1993), Schmitz (1997), Amaral (2001), que os agentes locais são os mais hábeis para promoverem a alocação de recursos pois são os maiores conhecedores das estruturas locais.

As despesas com saúde complementar apresentaram um baixo coeficiente $(0,0011)$ demonstrando que o tal investimento tem baixo poder de impactar na trajetória de desenvolvimento local. Acredita-se que esse fato pode ser decorrente da inviabilidade econômica de promover o surgimento de empresas ligadas ao desenvolvimento de produtos e serviços de alta complexidade tecnológica na ampla maioria dos municípios, visto que esses não têm demanda suficiente para manter essas estruturas, assim sendo, o crescimento apresentado seria fruto do surgimento de pequenas empresas - clinicas, ambulatórios e pequenos hospitais - enquanto a parte desses recursos que é alocada em alta complexidade acaba por concentrar-se nos grandes centros, nos polos regionais ou ser utilizada na importação de produtos e equipamentos de alta tecnologia.

A única variável que se apresentou inversamente relacionada à variável explicada foi o Número de agentes comunitários para cada 100 mil habitantes, está diretamente relacionada à Cobertura do programa ESF que apresentou um baixo coeficiente $(0,0017)$ mostrando pouco poder de impacto sobre o nível do PIB per capita nos 399 municípios analisados. Como ao longo do período analisado a média da variável cobertura do programa ESF foi $84 \%$, percebe- se que o programa ainda encontra-se em fase de implementaçáo, aliado a isso, soma-se à natureza do trabalho do agente comunitário de saúde focado na prevençáo e promoção de saúde do qual se espera um retorno a longo prazo, não sendo assim passível de percepção dentro de um modelo de dados em painel não defasados.

A capacidade explicativa do modelo como um todo apresentada pelo coeficiente $\mathrm{R}^{2}$ ajustado é de 0.4634 ou $46 \%$, como já afirmado o modelo focou intencionalmente nas variáveis de saúde, não incluindo assim todos os demais vetores que compóe o PIB, que se inclusos elevariam o poder explicativo do modelo.

\section{Modelo cuja variável dependente é o IPDM.}

Utilizando o IPDM como variável independente, chegou-se a um modelo de efeitos fixos, que foi selecionado, utilizando-se os testes de Chow, Hausmann e Breusch-Pagan. Em todos os testes rejeitou-se a hipótese nula a um índice de confiança de 5\%.

Com três variáveis significativas, o modelo inicial apresentou problemas de autocorrelaçáo, fato já esperado visto que, as variáveis levantadas na hipótese deste trabalho são todas referentes ao sistema público de saúde, sendo assim altamente relacionadas. O problema de autocorrelação foi resolvido utilizando o comando robust que gera um modelo 
de efeitos fixos com erros padrão robustos, mesmo método utilizado no modelo anterior. $\mathrm{O}$ modelo é apresentado na tabela 4 a seguir.

Tabela 4 - Resumo do modelo de efeitos fixos para o IPDM, com erros robustos.

\begin{tabular}{llrc}
\hline Variável & Coeficientes & P Valor & Erro padráo robusto \\
\hline Log.Desp. total per capita & 0,066 & 0,0 & 0,011 \\
\hline Log.Desp. Recursos próprios & 0,082 & 0,0 & 0,01 \\
\hline Log.Desp. Pessoal & - & - & - \\
\hline Log. No ACS & $-0,002$ & 0,87 & 0,01 \\
\hline Log. Saúde Complementar & 0,0003 & 0,0 & 0,0001 \\
\hline Cobertura ESF & 0,00004 & 0,75 & 0,0004 \\
\hline F & 76,75 & 0,0 & \\
\hline $\mathrm{R}^{2}$ & 0,3201 & \\
\hline
\end{tabular}

Fonte: Elaborado pelo autor, 2020.

O modelo, que utiliza como variável explicada o IPDM, que apresentou o melhor ajuste, possui três variáveis estatisticamente significativas, sendo elas: a) Despesa total per capita; b) Despesa com recursos próprios; c) Despesa com saúde complementar.

Todos os coeficientes estatisticamente significativos apresentaram valor positivo, ou seja, diretamente relacionado com a variável explicada. $\mathrm{O}$ único coeficiente negativo foi novamente o Número de agentes comunitários, assim como no modelo anterior, porém neste modelo a variável não é estatisticamente significativa, como dito anteriormente a um valor de 5\%. Implementos no sistema de saúde, de uma forma geral, tendem a elevar o IPDM, sendo o maior efeito apresentado pela variável - Despesas com recursos próprios, utilizada como proxy da gestáo municipal, pois é nessa categoria de recursos que se observa a maior autonomia dos agentes locais para determinar sua alocação. Esse coeficiente mostra que um aumento em $1 \%$ nos dispêndios com mão-de-obra especializada em saúde, gera um implemento de $0,082 \%$ no IPDM.

Enquanto o modelo anterior - PIB per capita - apresentou como variável mais relevante as despesas totais, este modelo, mais focado no desenvolvimento social tem como variável mais relevante as Despesas com recursos próprios, esse fato corrobora com a argumentação de que os agentes locais promoverão a alocação mais eficientes de recursos por serem os maiores conhecedores das dificuldades e especificidades locais, sejam culturais, institucionais ou de qualquer outra natureza. Essa alocação não se dará com intuito de fomentar a economia, mas sim, de elevar os níveis de qualidade de vida tal como observados pelo índice proposto pelo IPARDES. Novamente encontra-se resultados que convergem com literatura acerca das teorias de desenvolvimento local e regional, como por exemplo os trabalhos de Ultramari e Duarte (2011) e Amaral Filho, 2001, que colocam o agente local no centro do processo decisório por ser o maior conhecedor das estruturas institucionais locais. 
A segunda variável com o maior coeficiente foi Despesas totais per capita, que representa todo o aporte de recursos feito dentro do território municipal, independente da origem dos recursos, dividido pelo número de habitantes. $\mathrm{O}$ coeficiente relacionado a esta variável apresentou valor igual a 0,066, indicando que um aumento de $1 \%$ nas despesas totais per capita gera um aumento no IPDM de 0,066\%. Como dito anteriormente essa variável não apresenta discricionariedade, convergindo com a ideia de Granados (2002) de que em se tratando de saúde não há despesas, todos os valores devem ser entendidos como investimento. A última variável validada pelo modelo foi o dispêndio com a saúde complementar, ou seja, a contratação de serviços do setor privado pelo sistema público de saúde. O coeficiente demonstra que para cada $1 \%$ de aumento nesse gênero de contratação o IPDM aumenta $0.0003 \%$.

Mantendo assim um indicativo de baixa capacidade de impactar sobre o bem-estar social, assim como no econômico, como foi apresentado no modelo anterior. Já no que tange a capacidade explicativa do modelo como um todo apresentada pelo coeficiente $\mathrm{R}^{2}$ ajustado overall é de 0,3201 ou $32 \%$.

Ambos os modelos validaram três variáveis em comum, sendo elas: a) Despesas totais per capita; b) Despesas com pessoal; c) Percentual da despesa total utilizado na saúde complementar.

Apenas a variável denominada Despesas com recursos próprios foi validada apenas pelo modelo que tem como variável explicada o PIB per capita. As demais variáveis náo apresentaram significância estatística suficiente para permanecerem no modelo. A seguir é apresentado na tabela 5 resumo comparando os resultados obtidos em ambos os modelos.

Tabela 5 - Comparativo dos resultados obtidos para os modelos PIB e IPDM para os 399 municípios do Paraná, no período 2007 - 2011.

\begin{tabular}{l|l|l|l|l}
\hline Variável & $\begin{array}{l}\text { Coeficientes modelo } \\
\text { PIB }\end{array}$ & Sig. & $\begin{array}{l}\text { Coeficientes } \\
\text { modelo IPDM }\end{array}$ & Sig. \\
\hline Log.Desp. total per capita & 0,309 & 0,0 & 0,066 & 0,0 \\
\hline Log.Desp. Recursos próprios & 0,302 & 0,0 & 0,082 & 0,0 \\
\hline Log.Desp. Pessoal & - & - & - & - \\
\hline Log. No ACS & $-0,102$ & 0,04 & $-0,002$ & 0,87 \\
\hline Log. Saúde Complementar & 0,001 & 0,0 & 0,0003 & 0,0 \\
\hline Cobertura ESF & 0,001 & 0,009 & 0,00004 & 0,75 \\
\hline
\end{tabular}

Fonte: Elaborado pelo autor, 2020.

A obtenção de uma significância estatística para a variável Despesas totais demonstra a importância de um sistema de saúde público para a população, ao estar diretamente relacionado com ambas as variáveis independentes e ter valor superior a zero, demonstra, como afirmado anteriormente, que deve-se utilizar o termo despesa apenas contabilmente, mas, em se tratando de políticas públicas o montante de recursos destinados à saúde deve ser considerado um investimento, como afirmam Granados (2002) e Hussain (2009), pois, 
promove um efeito positivo, diferente de zero, na trajetória de crescimento econômico da região e quando considera-se questôes de cunho social, o mesmo efeito é observado.

A variável despesas com recursos próprios foi significativa para ambos os modelos, esse fato é consonante às teorias de desenvolvimento regional e local, que afirmam que os agentes do local, e não esferas superiores da administração pública, por meio da "ação coletiva” (SCHMITZ, 1997), são os mais capazes de promover a correta alocação de recursos, e os agentes locais o fazem de forma harmônica com as especificidades do local, pois ao ampliar os poderes de decisão dos agentes locais, aumenta-se também suas responsabilidades, colocando "nas mãos desses o destino da economia local" (AMARAL FILHO, 2001, p.267) fomentando assim uma melhor "organização social regional" como definiu Boisier (1988).

A variável despesas com pessoal foi omitida de ambos os modelos por apresentar colinearidade, esta variável foi tomada como proxy do capital humano disponível no sistema, no entanto, a forma como é disponibilizada pelo setor público, em proporção das despesas totais, inviabilizou uma análise econométrica de ambas as variáveis em conjunto.

Os dispêndios com saúde complementar mostraram-se significativos em ambos os modelos, no entanto, com baixos valores para seus coeficientes, principalmente se comparado às demais variáveis, isso demonstra que, embora possua um vetor positivo, como o fomento ao surgimento e expansão do setor privado. Esse efeito é diminuto quando comparado ao investimento direto observado em variáveis como a despesa com recursos próprios. Isso reforça o intuito de manter um sistema majoritariamente público e universal. Essa assertiva se faz ainda mais verdadeira quando observado o impacto dessa forma de dispêndio no modelo que engloba variáveis de cunho social, modelo IPDM, onde o coeficiente é de 3 décimos de milésimo.

Como dito anteriormente, outra causa para um impacto tão diminuto é a parte desses recursos que são exportadas via importação de produtos de alta complexidade tecnológica, não produzidos localmente, seja por questóes de demanda ou de know how tecnológicos ou patentes. Mesmo assim, o setor público se mostra dependente desse estrutura, pois, ela cresceu proporcionalmente ao sistema, mostrando uma ineficiência do gestor público em criar mecanismos para atender a oscilante demanda por serviços de saúde.

A cobertura do programa ESF também apresentou um valor muito pequeno, no entanto, positivo para ambos os modelos, acredita-se que esse coeficiente, estatisticamente significativo, porém, muito baixo, seja em decorrência do programa ainda não ter atingido sua plenitude, estando ainda em fase de implementação em muitos municípios. A média observada de área de cobertura atendida pelo programa foi de $84 \%$, onde o menor valor para o último ano analisado ainda era de $21 \%$, que pode indicar uma percepção errada do gestor local quanto ao programa, visto que, esse traz retornos de longo prazo na forma de economia dentro do sistema de saúde no que tange a tratamentos médicos. Que serão evitados via promoção da saúde, assim como economicamente, via aumento da produtividade do trabalho como afirmado por Fogel (1994, 1997), Ruger (2006); Schultz (2002); Miguel e Kremer (2004); Bleakley (2006), enquanto no curto prazo não se percebe grandes resultados do programa, se náo há percepção do eleitorado, o gestor pode tender a dar menor importância ao programa, retornando à questão política da gestão pública. 
O número de agentes comunitários de saúde mostrou-se inversamente correlacionado com ambas as variáveis explicadas, no entanto, foi significativo apenas no modelo PIB per capita. Acredita-se que este valor seja em decorrência do programa ainda estar sendo implementado e do fato de que o objetivo do trabalho desses agentes é o foco no longo prazo. No período analisado ainda não havia o Paraná atingido o número de agentes comunitários de saúde que o programa considera ideal, um agente para cada 3 mil habitantes. Aliado a isso tem-se que a natureza do programa tem seus objetivos no longo prazo, o agente comunitário de saúde busca prevenir e promover a saúde na comunidade em que trabalha, assim o resultados desse programa será mais facilmente observados em períodos posteriores.

\section{CONCLUSÓES}

O objetivo deste trabalho foi avaliar se a estrutura de saúde pública causa impactos sobre o desenvolvimento local e regional, tomando como objeto de estudo os 399 municípios do Estado do Paraná. Ao encontrar três (3) variáveis estatisticamente significativas em ambos os modelos, e mais duas no modelo PIB, pode-se sugerir que a estrutura de saúde pública disposta para essa populaçáo impacta sob o desenvolvimento, e o faz de forma positiva.

No modelo IPDM, que incluiu na composição da variável Dependente - variáveis sociais, a que apresentou relevância foi a de despesas com recursos próprios, corroborando com o conjunto de teorias de desenvolvimento local que entendem o agente como o mais capacitado para deliberar sobre a alocação de recursos, por ser o maior conhecedor de suas especificidades e dar melhor aplicação aos recursos.

No modelo PIB per capita, além das variáveis identificadas no modelo anterior, foram significativas as variáveis Número de agentes comunitários de saúde e a área de cobertura do programa estratégia saúde da família. Essas variáveis foram utilizadas como proxy da amplitude do sistema público de saúde voltado para a prevenção e promoção de saúde. $\mathrm{O}$ programa estratégia saúde da família ainda não alcançou seu objetivo de oferecer cobertura plena à população de todos os municípios do país, o mesmo é observado no estado do Paraná onde a cobertura média é de $84 \%$, mesmo assim, o programa se mostra como um vetor positivo em ambos os modelos, mas, estatisticamente significativo apenas no modelo PIB per capita, tendo assim mais ênfase no crescimento da riqueza nacional do que na elevação dos níveis de qualidade de vida.

Tal fato pode ser decorrente da implementação da produtividade do trabalho do trabalhador médio quando saudável, como observado nos trabalhos de Behrman e Rosenzweig (2001); Thomas e Frankenberg (2002); Suhrcke et al.(2005). Um trabalhador mais saudável consequentemente resultará em uma maior produtividade, impactando assim no produto nacional, porém, não impactando na redução os níveis de concentração de renda, que pode interferir na qualidade de vida da populaçáo pela dificuldade de acesso aos serviços de saúde, a aquisição de medicamentos e a resolutividade de problemas sociais.

Ainda foi possível observar que apesar do impacto positivo da saúde na economia, algumas variáveis obtiveram resultados pouco significativos que tencionam para as dificuldades de gestão na saúde. A saúde é um campo complexo que envolve não somente o processo saúde-doença, encontra-se relacionado aos recursos humanos, tecnológicos, 
infraestrutura e principalmente o contexto social da população atendida. Portanto, vale ressaltar que estatisticamente a saúde tem um impacto positivo na economia, mas, isso não permite afirmar que o Estado oferece um sistema público de qualidade e que cumpre os seus preceitos básicos da universalidade, integralidade e equidade no atendimento à população.

É de notório saber que a saúde apresenta um quadro repleto de desigualdades, insatisfação dos usuários, ineficiência na atenção básica na resolutividade dos problemas, ausência de capacitação e comprometimento profissional entre outros problemas que podem gerar investimentos sem resolutividade por parte do Estado.

Observou-se na pesquisa que o número de agentes comunitários de saúde foi a única variável que apresentou um coeficiente negativo. Acredita-se que isso se dá em decorrência da natureza do serviço ofertado pelos agentes, cujo objetivo é a promoção da saúde, ou seja, seu enfoque não é na doença, nas consultas médicas ou em serviços de alta e média complexidade que geram ônus ao Estado. A atividade do agente comunitário é orientar e monitorar a população de sua área de abrangência para que a mesma não fique doente, consequentemente o ganho populacional é em melhores condições de saúde e economia no setor de saúde.

Não foi possível analisar a variável Despesas com pessoal, que foi utilizada como proxy da quantidade de capital humano no sistema, pois essa é disponibilizada apenas como proporção da despesa total, resultando assim em autocorrelação, os dados foram retirados do modelo. Aprimorar os modelos buscando inserir outra variável para capital humano e reavaliando o uso do número de agentes comunitários de saúde como variável defasada fica como sugestão para pesquisas futuras na área.

Conclui-se que a existência de um sistema público de saúde gera impactos positivos sobre o crescimento da riqueza nacional, já que encontra-se relacionada com a contratação de recursos humanos, serviços, medicamentos e com geração de recursos financeiros provenientes dos serviços prestados à população que está em busca do atendimento.

\section{REFERÊNCIAS}

ALMEIDA FILHO, Niemeyer. O desenvolvimento da América latina na perspectiva da CEPAL dos anos 90: Correção de rumos ou mudança de concepção? Campinas: IE/ UNICAMP, 2001.

AMARAL FILHO Jair. A endogeneização no desenvolvimento econômico regional e local. Revista planejamento e políticas públicas. Rio de Janeiro: Ipea, n.23, jun. 2001.

ANDRÉN, Daniela; PALMER, Edward. The effect of sickness on earnings. Working Papers in Economics, Department of Economics, Gothenburg: Gothenburg University, 2001.

ARORA, Suchit. Health, human productivity, and long-term economic growth. The Journal of Economic History, v.61. P. 699-749. Cambridge: [s.n.] 2001. 
ASSOCIAÇÃO PAULISTA DE MEDICINA. Em 2014, Governo não gastou o previsto com o SUS. Disponível em: http://apmsantos.org.br/noticias/616-em-2014governo-nao-gastou-o-previsto-com-o-sus Acesso em: 08 mar. 2020.

BARRO, Robert. Health and economic growth. Paper Prepared for the Pan American Health Organization. Washington-DC: PAHO, 1996.

BARRO, Robert; LEE, Jong-Wha. Sources of economic growth. Carnegie-Rochester Conference Series on Public Policy. New York: v.40, p.1-46, 1994.

BARRO, Robert; SALA-I-MARTIN, Xavier. Economic growth. New York: McgrawHill. 1995.

BARTEL, Ann. TAUBMAN, Paul. Health and labor market success: the role of various diseases. The Review of Economics and Statistics, Massachusetts: MIT Press, v.61, 1979.

DataSUS, Base De Dados Eletrônica Do Sistema Único De Saúde. Disponível em: http://tabnet.datasus.gov.br/cgi/tabcgi.exe?sih/cnv/niuf.def Acesso em: 13 jan. 2020.

BECKER, Gary. Investment in Human Capital: A Theoretical Analysis. The Journal of Political Economy, Chicago: Investment in Human Beings, v. 70, No. 5, 1962.

BEHRMAN, Jere; ROSENZWEIG, Mark. The Returns to Increasing Body Weight. PIER Working Paper n.01, [s.l.] Penn Institute for Economic Research, 2001.

BENHABIB, Jess; SPIEGEL, Mark. The role of human capital in economic development evidence from aggregate cross-country data. Journal of Monetary Economics, Chicago, v.34, n.2, out. 1994 .

BEN-PORATH, Yoran. The Production of Human Capital and the Life Cycle of Earnings. The Journal of Political Economy, New York, n.8, 1967.

BHARGAVA, Alok; JAMISON, Dean; LAU, Lawrence; MURRAY, Christopher. Modeling the Effects of Health on Economic Growth. Journal of Health Economics, Houston, 2001.

BIRDSALL, Nancy; SINDING, Steven. How and Why Population Matters: New Findings. New Issues. Oxford: 2001.

BIRDSALL, Nancy; SINDING, Steven; KELLEY, Allen. Population Matters:

Demographic Change, Economic Growth, and Poverty in the Developing World. Oxford: Oxford University press, 2001.

BLEAKLEY, Hoyt. Disease and Development: Evidence from Hookworm Eradication in the American South. The Quarterly Journal of Economics, Cambridge, v.51, 2007. 
BLEAKLEY, Hoyt. Malaria in the Americas: A Retrospective Analysis of Childhood Exposure. Documento CEDE 2006-35, Universidad De Los Andes, set. 2006.

BLOOM, David; CANNING, David; SERVILLA, Jaypee. The Demographic Dividend: A New Perspective on the Economic Consequences of Population Change. Ed. Santa Monica, 2003.

BLOOM, David; SACHS, Jeffrey. Geography. Demography, and Economic Growth in Africa. Brookings Papers on Economic Activity, Cambidge, n.2, 1998.

BLOOM, David; WILLIAMSON, Jeffrey. Demographic Transitions and Economic Miracles in Emerging Asia. World Bank Economic Review, [s.l.] the Word Bank, v.12, n.3, 1998.

\section{BOISIER, Sergio. Política Econômica, Organização Social e Desenvolvimento}

Regional. Fortaleza: Banco do Nordeste do Brasil S.A, 1988.

BRASIL. Lei Complementar n.147 de 7 de agosto de 2014. Presidência da República, Casa Civil. Disponível em: http://www.planalto.gov.br/ccivil_03/leis/LCP/Lcp147.htm Acesso em: 25 jun. 2020.

CAMERON, Colin; TRIVEDI, Pravin. Microeconometrics Using Stata. Houston: Stata Press, 2010.

CASE, Anne; PAXSON, Christina; ABLEIDINGER, Joseph. Orphans in Africa: Parental Death, Poverty, and School Enrollment. Demography, Princeton: Princeton University, ago. 2004.

CASELLI, Francesco; ESQUIVEL, Gerardo; LEFORT, Fernando. Reopening the Convergence Debate: A New Look at Cross Country Growth Empirics. Journal of Economic Growth. Cambridge: Harvard University Press, 1996.

CHIRIKOS Thomas; NESTEL, Gilbert. Further. Evidence on the Economic Effects of Poor Health. The Review of Economics and Statistics. Massachusetts: The MIT press, v.67, n.1, 1985 .

COALE, Ansley; HOOVER, Edgar. Population Growth and Economic Development in Low-Income Countries: A Case Study of India冈s Prospects. Princeton: Princton University Press, 1958.

CONILL, Eleonor Minho. Ensaio histórico-conceitual sobre a Atenção Primária à Saúde: desafios para a organização de serviços básicos e da Estratégia Saúde da Família em centros urbanos no Brasil. Cad. Saúde Pública, Rio de Janeiro: [s.n.] 2008. 
CONSELHO REGIONAL DE MEDICINA DO PARANÁ.

Disponível em: http://www.crmpr.org.br/webp/tools/pagingInterceptor.

jsp?componentPid=133\&pageNumber=1 Acesso em: 09 mai. 2020.

CONTOYANNIS, Paul; RISE, Nigel.The Impact of Health on Wages: Evidence from British Household Panel Survey. Empirical Economics, London: European Society for Population Economics, v.74, n.5, 2001.

CUTLER, David; DEATON, Angus; LLERAS-MUNEY, Aadriana. The Determinants of Mortality. Journal of Economic Perspective, Chicago: American Economic Association, v.20. 2006.

DOW, Will et al. Health Care Prices, Health and Labor Outcomes: Experimental Evidence. Labor and Population Program Working Paper. Santa Monica/CA: UCLA, v.97, 2001.

FIGUEIREDO FILHO, Britto; SILVA, José Alexandre. Desvendando os Mistérios do Coeficiente de Correlação de Pearson. Revista Política Hoje, Pernambuco: [s.n.] v.18, n. $1,2009$.

FOGEL, Rober William. New Findings on Secular Trends in Nutrition and Mortality: Some Implications for Population Theory. Handbook of Population and Family Economics. Amsterdam: Elsevier, 1997.

FOGEL, Robert William. Economic Growth, Population Theory, and Physiology: The Bearing of Long-Term Processes on the Making of Economic Policy. The American Economic Review, [s.1.] STOR, v.84, n.3, p.369-95, 1994.

FOLEY, Duncan. Stabilization of Human Population Through Economic Increasing Returns. Economics Letters, v.68, Amsterdam: Elsevier. 2000.

FUENTES, Juan Ramón; CONYER, Roberto Tapia e FERNÁNDEZ, Miguel Lezana. La información em salud. Revista Panamericana de Salud Publica, Washington: [s.n.] v.12, 2002.

GALLUP, Jhon Luke; SACHS, Jeffrey. The Economic Burden of Malaria. Working Paper N. 52, Center for International Development, Cambridge: Harvard University, jul. 2000.

GAMBIN, Lynn. Gender Differences in the Effect of Health on Wages in Britain. Department of Economics and Related Studies, New York: University of York, 2004.

GRAÇA, Luiz. Iniciativas para reduzir e prevenir o absenteísmo por incapacidade para o trabalho (Working paper) Anais do XXVII Encontro Nacional de Economia. Belém/PA: ANPEC, 1999. 
GRANADOS, José Tapia. Investiment in heslth: Social and economic retuns. Revista Panamericana de Salud Publica, Washington: [s.n.] v.1, 2002.

GROSSMAN, Michael. The Demand for Health, 30 Years Later: A Very Personal Retrospective and Prospective Reflection. Journal of Health Economics. New York: Elsevier, v.23. 2004.

GROSSMAN, Michael; KAESTNER, Robert. Effects of Education on Health. Michigan: University of Michigan Press. 1997.

GRUBER, Jonathan; HANRATTY, Maria. The Labor-Market Effects of Introducing National Health Insurance: Evidence from Canada. Journal of Business and Economic Statistics. Princeton: American Statistic Association, v.13, n.2, 1995.

GUJARATI, Damodar. Econometria básica. 4. ed. Tradução de Maria José Cyhlar Monteiro, Rio de Janeiro: Elsevier, 2006.

GUSTMAN, Alan; STEINMEIER, Thomas. A Disaggregated, Structural Analysis of Retirement by Race, Difficulty of Work and Health. Review of Economics and Statistics. Cambridge: NBER, v.68, n.3, 1986.

HAMOUDI, Amar; SACHS, Jeffrey. Economic Consequences of Health Status: A Review of the Evidence. Working Paper N. 30. Cambridge: Harvard Center for International Development, 1999.

HANSEN, Jörgen. The Effect of Work Absence on Wages and Wage Gaps in Sweden. Journal of Population Economics, London: European Society for Population Economics, v.13, n.1, 2000.

HUSSAIN, Muhammad Jami. Contribution of Health to Economic Development: A Survey and Overview. Economics E-journal Discussion Paper, 2009

INSTITUTO BRASILEIRO DE GEOGRAFIA E ESTATÍSTICA (IBGE). Área Territorial Oficial - Consulta por Unidade da Federação. 2020a.

INSTITUTO BRASILEIRO DE GEOGRAFIA E ESTATÍSTICA (IBGE). Contas Regionais do Brasil - 2005-2009. 2020b.

INSTITUTO BRASILEIRO DE GEOGRAFIA E ESTATÍSTICA (IBGE). Disponível em: http://seriesestatisticas.ibge.gov.br/lista_tema.aspx?op=0\&no=1 Acesso em: 15 out. 2020.

INSTITUTO BRASILEIRO DE GEOGRAFIA E ESTATÍSTICA (IBGE). Pesquisa nacional por amostra de domicílios. Volume 31. Ministério do Planejamento, Orçamento e Gestáo Instituto Brasileiro de Geografia e Estatística, 2011. 
INSTITUTO DE PESQUISA ECONÔMICA APLICADA (IPEADATA). Dados

macroeconômicos e regionais. Disponível em: http://www.ipeadata.gov.br Acesso em: 01 jan. 2020.

KALEMLI-OZCAN, Senem; RYDER, Harl; WEIL, David. Mortality Decline, Human Capital Investment, and Economic Growth. Journal of Development Economics, Houston: University of Houston, jun. 2000.

KELLEY, Allen; SCHMIDT, Robert. Economic and Demographic Change: A Synthesis of Models, Findings, and Perspectives. Population Matters: Demographic Change, Economic Growth, and Poverty in the Developing World. Oxford: Oxford University Press. 2001.

KINUGASA, Tomoko; MASON, Andrew. Why Countries Become Wealthy: The Effects of Adult Longevity on Saving. World Development, [s.1.] Elsevier, v.35, n.1, p.1-23, 2007.

KNIGHT, Malcom; LOAYZA, Norman; VILLANUEVA, Delano. "Testing the Neoclassical Growth Model”, IMF Staff Papers, [s.1.] International Monetary Fund, v.40, p. 512-541, dez. 1993.

KNOWLES, Stephen; OWEN, Dorian. Education and health in an effective-labour empirical growth model. Economic Record, Amsterdam: Elsevier, v.14, 1997.

LEE, Ronald; MASON, Aandrew; MILLER, Timothy. Saving, Wealth, and Population, Population Matters: Demographic Change, Economic Growth, and Poverty in the Developing World. Oxford: University Press. 2007.

LEE, Ronald; MASON, Andrew; MILLER, Timothy. Life Cycle Saving and the Demographic Transition: The Case of Taiwan. Population and Development Review. v.26, p.194-219, Hong Kong: Population Council, 2000.

LI, Ruowei; Chen, Xuecun; YAN, Huaicheng; DEURENBERG, Paul; GARBY, Lars; HAUTVAST, Joseph. Functional Consequences of Iron Supplementation in IronDeficient Female Cotton Workers in Beijing, China. New York: American Journal of Clinical Nutrition. 1994.

LLERAS-MUNEY, Adriana. The Relationship Between Education and Adult Mortality in the U.S. New York: Review of Economic Studies, 2005.

LUCAS, Robert. On the Mechanics of Economic Development. Journal of Monetary Economics. North-Holland: Elsevier Science Publishers, n.22, p.3-42, 1988.

LUFT, Harold. The Impact of Poor Health on Earnings. The Review of Economics and Statistics, Massachusetts: The MIT press, v.57, 1975. 
MALTHUS, Thomas. Na essay on the principle of population. New York, Liberty Fund, 1826.

MANKIW, Gregory; ROMER, David; WEIL, David. A Contribution to the Empirics of Economic Growth. Quarterly Journal of Economics. Cambidge: Harvard Press, n.107, p.407-38, ago. 1992.

MIGUEL, Edward; KREMER, Michael. Worms: Identifying Impacts on Education and Health in the Presence of Treatment Externalities. Cambridge: Econometric Society, 2004.

MINCER, Jacob. Investment in Human Capital and Personal Income Distribution. The Journal of Political Economy. v.66, n.4, p.281-302, Chicago: The University of Chicago Press, 1958.

MOFFETT, Jhon et al. Controlled Trial of Exercise for Low Back Pain: Clinical Outcomes, Costs, and Preferences. BMJ, [s.l.] BMJ Goup, n.319. 1999.

NAKAMURA, Wilson Toshiro et al. Determinantes de estrutura de capital no mercado brasileiro - análise de regressão com painel de dados no período 1999-2003. São Paulo: USP, 2007.

NERO, Carlos; Economia da Saúde: conceitos e contribuição para a gestão da saúde. Cap.1 O que é Economia da Saúde. Brasília: IPEA, 1995.

NEWHOUSE, Joseph. Free for All? Lessons from the RAND Health Insurance Experiment. Cambridge, Harvard University Press. 1993.

PELKOWASKI, Jodi; BERGER, Mark. The Impact of Health on Employment, Wages, and Hours Worked Over the Life Cycle. Quarterly Review of Economics and Finance, [s.l; s.n] 2004.

PENATTI, Izidro: ZAGO, José Sebastião; QUELHAS, Oswaldo. Absenteísmo: as consequências na gestão de pessoas. Anais do III SEGeT - Simpósio de Excelência em Gestão e Tecnologia, 2006.

PUTNAM, Robert David. The prosperous community: social capital and public life. New York: The American Prospect, 1993.

REBELO, Sergio. Long-Run Policy Analysis and Long-Run Growth. Journal of Political Economy. Cambridge, v.99, n.3, p.500-521 jun. 1991.

RIVERA, Berta; CURRAIS, Luis. Economic Growth and Health: Direct Impact Or Reverse Causation? Applied Economics Letters. [s.l.] Taylor \& Francis Journals, v.6, n.11, p.761-764, 1999a. 
RIVERA, Berta; CURRAIS, Luis. Income Variation and Health Expenditure: Evidence for OECD Countries. Review of Development Economics. [s.l.] v.3, n.3, p.258-267. $1999 \mathrm{~b}$.

RIVERA, Berta; CURRAIS, Luis. The Effect of Health Investment on Growth: A Causality Analysis. International Advances in Economic Research. Coruna: Springer, v.9, p.312-323, 2003.

ROBLES, Sylvia; GALANIS, Eleni. El câncer de mama em Américalatina y el Caribe.

Revista Panamericana de Salud Publica. Washington: [s.n.] v.12, 2002.

RUGER, Jhon. Health and the Economy. International Public Health: Diseases, Programs, Systems, and Policies. 2. ed. Boston: Boston press, 2006.

SACHS, Jeffrey. Macroeconomics and health: investing in health for economic development. Revista Panamericana de Salud Publica. Washington: [s.n.] v.12, 2002.

SAHN, David; ALDERMAN, Harold. The Effect of Human Capital on Wages and the Determinants of Labor Supply in a Developing Country. Journal of Development Economics. Av.29, n.2, p.157-183, Amsterdam: Elsevier, 1988.

SCHMITZ, Hubert. Collective efficiency and increasing returns. Working Paper, n. 50, Institute of Development Studies, Inglaterra: [s.n.] 1997.

SCHULTZ, Paul. Wage Gains Associated with Height as a Form of Health Human Capital. Discussion Paper No 841, Yal: Economic Growth Center, Yale Economic. 2002.

SMITH, James. Healthy Bodies and Thick Wallets: The Dual Relation Between Health and Economic Status. Journal of Economic Perspectives, Chicago: American Economic Association, v.13. Jun. 1999.

SOLOW, Robert. A Contribution to the Theory of Economic Growth. Quarterly Journal of Economics, Massachusetts: The MIT press, v.70 p.65-94, 1956.

STATA. Manual STATA 13. Disponível em: http://www.stata.com/manuals13/u.pdf Acesso em: 02 fev. 2020.

STRAUSS, John. Does Better Nutrition Raise Farm Productivity? Journal of Political Economy. V.94, Chicago: JSTOR, abr. 1986.

STRAUSS, John; THOMAS, Duncan. Health, Nutrition, and Economic Development. Journal of Economic Literature. V.36, Nevada: American Economic Association, 1998.

SUHRCKE, Marc. The Contribution of Health to the Economy in the European Union. Health and Consumer Protection Directorate General, Belgium: European Commission, 2005. 
SWAN, Trevor. Economic Growth and Capital Accumulation. The Economic Record, [s.l; s.n.] v.32, n.2, p. 334- 361. 1956.

THOMAS, Duncan; FRANKENBERG, Elizabeth. Health, Nutrition, and Economic Prosperity: A Microeconomic Perspective. Bulletin of the World Health Organization. [s.l.] World Health Organization, 2002.

ULTRAMARI, Clovis; DUARTE, Fábio. Desenvolvimento: Local e Regional. Rio de Janeiro: Ibpex, 2009.

VILLA, Hernando Agudelo. La revolución del desarrollo: origen y evolución de la Alianza para el Progreso. México: Editorial Roble, 1966.

WEIL, David. Accounting for the Effect of Health on Economic Growth. Quarterly Journal of Economics. Oxford: v.122, n.3, Jan. 2007.

WOOLDRIDGE, Jeffrey. Introdução à econometria: uma abordagem moderna. 2. ed. Tradução José Antônio Ferreira. São Paulo: Cengage Learning. 2010. 